\title{
Faktor-faktor yang Berhubungan dengan Tindakan Tidak Aman pada Pekerja di Proyek Pembangunan Apartemen Evencho Margonda
}

\author{
${ }^{1}$ Sempurna Bangun, ${ }^{2}$ Indriasari \\ ${ }^{1}$ Teknik Sipil Fakultas Teknik, Universitas Tama Jagakarsa, J1.TB Simatupang no 152 Tanjung Barat Jakarta \\ Selatan, $0217890966{ }^{2}$ Teknik Sipil Fakultas Teknik, Universitas Krisnadwipayana, Jl. Kampus Unkris \\ Jatiwaringin PO. Box 7774/Jat CM Jakarta 13077, 02184998529 \\ e-mail: amirhamzah@jagakarsa.ac.id
}

Receive: 12 Desember 2020 Accepted: 12 Januari 2021

\begin{abstract}
Unsafe action becomes a problem for most work accidents. This study focuses on the factors associated with unsafe actions caused by various kinds of causes or factors both within the worker and the work environment. The construction industry cannot be separated from the potential hazards that can cause work accidents. Analysis of unsafe actions is needed in an effort to prevent the number of accidents at work. The research was conducted using a cross sectional research design or method and included in descriptive research. The interview questionnaire was addressed to workers as many as 75 workers. Research variables aimed at resource persons include knowledge, motivation, supervision, $K 3$ training and the availability of PPE. The assessment of unsafe actions was carried out by entering the results of the interviewee's questionnaire using the SPSS V20 application. From the results of the questionnaire research, 70 workers found unsafe actions were carried out by $44 \%$ of the workers. the lack of knowledge factor was $18.7 \%$, the low motivation factor was $46.7 \%$, the supervisory factor was less than 9.3\%, the factor of workers who did not attend K3 training was $17.3 \%$, and the factor of lack of availability of Personal Protective Equipment was $10.7 \%$ of all factors with the strongest association with unsafe action. Monitoring and training are required to increase the knowledge of workers so that they can better avoid accidents caused by the factors that have been studied.
\end{abstract}

Keywords: Unsafe measures, Construction Industry, Factors Unsafe action factor

\begin{abstract}
Abstrak
Tindakan yang tidak aman menjadi masalah bagi sebagian besar kecelakaan kerja. Penelitian ini memfokuskan pada faktor-faktor yang terkait dengan tindakan tidak aman yang disebabkan oleh berbagai macam penyebab atau faktor baik di lingkungan pekerja maupun lingkungan kerja. Industri konstruksi tidak lepas dari potensi bahaya yang dapat menyebabkan kecelakaan kerja. Analisis tindakan tidak aman diperlukan dalam upaya mencegah banyaknya kecelakaan kerja. Penelitian dilakukan dengan menggunakan desain atau metode penelitian cross sectional dan termasuk dalam penelitian deskriptif. Kuesioner wawancara ditujukan kepada pekerja sebanyak 75 pekerja. Variabel penelitian yang ditujukan pada nara sumber meliputi pengetahuan, motivasi, supervisi, pelatihan K3 dan ketersediaan APD. Penilaian tindakan tidak aman dilakukan dengan memasukkan hasil kuesioner narasumber menggunakan aplikasi SPSS V20. Dari hasil penelitian kuisioner, 70 pekerja menemukan tindakan tidak aman yang dilakukan oleh $44 \%$ pekerja. Faktor pengetahuan kurang $18,7 \%$, faktor motivasi rendah $46,7 \%$, faktor pengawasan kurang dari 9,3\%, faktor pekerja yang tidak mengikuti pelatihan $\mathrm{K} 3$ sebanyak $17,3 \%$, dan faktor kurangnya ketersediaan alat pelindung diri. Peralatan adalah 10,7\% dari semua faktor dengan hubungan terkuat dengan tindakan tidak aman. Pemantauan dan pelatihan diperlukan untuk meningkatkan pengetahuan pekerja agar dapat lebih terhindar dari kecelakaan yang disebabkan oleh faktor-faktor yang telah dipelajari.
\end{abstract}


Kata Kunci: Tindakan tidak aman, Industri Konstruksi, Faktor Faktor tindakan tidak aman

\section{PENDAHULUAN}

Diukur dengan kematian terkait pekerjaan, konpensasi pekerja, cedera dan kematian dibanyak bagian dunia, industri konstruksi telah diidentifikasi sebagai salah satu industri yang paling berbahaya. Keselamatan di tempat kerjamerupakan fenomena yang kompleks, keamanan industri telah mengalami perubahan yang signifikan selama beberapa dekade terakhir. Korban kecelakaan pada sektor konstruksi menjadi yang paling penting karena terus bertambah tinggi. Pekerja konstruksi yang bekerja dalam konstruksi menghadapi kematian yang lebih tinggi daripada pekerja di industri lain. (Chong. H.Y,2014:503)

Tindakan tidak aman (unsafe action) ialah suatu tindakan dimana pekerja yang tidak memenuhi keselamatan sehingga beresiko mengakibatkan kecelakaan kerja. Menurut Du Pont tahun 2015, bahwa 96\% injuries (luka) disebabkan oleh unsafe action dan $4 \%$ disebabkan unsafe condition. National Safety Council dalam penelitiannya menyatakan bahwa $87 \%$ kecelakaan kerja disebabkan oleh unsafe action, dan $78 \%$ disebabkan oleh mekanis (Du Pont, 20015:8). Terjadinya kecelakaan kerja dikarenakan ada dua golongan.Golongan pertama yaiu faktor manusia (human factor) (Reason,1997:34). Golongan kedua adalah faktor mekanis dan lingkungan (unsafe condition) Penelitian yang dilakukan Yanti (2011), 98\% dari 69 pekerja pernah mengalamikecelakaankerja,diantaranyaterkena benda tajam dan terjepit. Perilaku sikap manusia menjadi salah satu faktor terjadinya kecelakaan kerja dengan $55,1 \%$ berpengetahuan rendah, $46,4 \%$ memiliki sikap negatif, dan $68 \%$ memiliki perilaku tidak aman.

Penelitian terbaru yang dilakukan Depita (2019), jumlah kecelakaan kerja pada proyek Grand Sedayu Apartemen tahun 2018 adalah 10 kasus. Terdapat 5 indikator faktor faktor penyebab kecelakaan kerja yang dominan yaitu faktor penggunaan alat pelindung diri untuk kepentingan keselamatan kerja, faktor penggunaan helm pengaman, faktor lantai kerja licin, faktor pencahayaan di tempat kerja, faktor terpleset atau terjatuh.

Berdasarkan survey pertama yang dilaksanakan pada tanggal 17 Februari 2020, PT PP Tbk telah memberikan Alat Pelindung Diri berupa safety shoes dan safety helmet untuk digunakan pekerja bangunan konstruksi saat bekerja. Dari 10 pekerja yang telah diamati, 8 pekerja $(80 \%)$ pekerja bangunan pada proyek pembangunan Apartemen Evenciio, Depok tidak patuh atau taat dalam mempergunakan Alat Pelindung Diri tersebut. Helm yang seharusunya digunakan untuk melindungi bagian kepala disalahgunakan menjadi tempat menaruhnya paku dan pekerja lebih memilih bekerja menggunakan alas kaki saja daripada menggunakan sepatu karenamenurut mereka bekerja menggunakan alas kaki saja lebih nyaman dibandingkan dengan menggunakan sepatu.

Berdasarkan hal tersebut,penyusun tertarik untuk mengambil permasalahan mengenai Faktor-Faktor yang Berhubungan dengan Tindakan Tidak Aman (Unsafe Action) pada Pekerja di Proyek Pembangunan Apartemen Evencho. 


\section{METODE PENELITIAN}

\section{Desain penelitian}

Jenis penelitian ini bersifat analitik dengan pendekatan kuantitatif dengan menggunakan desain penelitian cross sectional (potong lintang) yaitu suatu penelitian untuk mempelajari dinamika korelasi antara faktor - faktor resiko dan efek dengan cara pendekatan observasi atau pengumpulan data sekaligus pada suatu waktu saja (poin time approach) (Notoatmojo).

\section{Lokasi dan Waktu Penelitian}

Penelitian ini dilaksanakan di Proyek Pembangunan Apartemen Evenciio, Margonda. Penelitian ini dilakukan dalam bulan juli 2020.

\section{Populasi Dan Sampel Penelitian}

\section{Populasi}

Populasi menurut Sugiyono (2017:80) adalah wilayah generalisasi yang terdiri atas obyek atau subyek yang mempunyai kualitas dan karakteristik tertentu yang ditetapkan oleh peneliti untuk dipelajari dan kemudian ditarik kesimpulannya.Berdasarkan pengertian populasi tersebut maka yang menjadi populasi sasaran pada penelitian ini adalah pekerja Di Proyek Pembangunan Apartemen Evenciio, Margonda dengan jumlah keseluruhan sebanyak 300 pekerja.

\section{Sampel}

Husein Umar (2008:141), mengemukakan bahwa ukuran sampel dari suatu populasi dapat menggunakan bermacam - macam cara, salah satunya adalah dengan menggunakan teknik Slovin dengan rumus sebagai berikut:

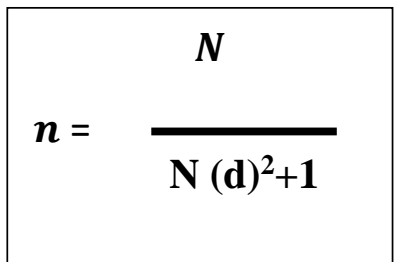

Keterangan:

$\boldsymbol{n} \quad$ : Jumlah sampel

$\boldsymbol{N} \quad$ : Jumlah populasi

$\mathrm{d}^{2} \quad$ : Tingkat ketelitian yang diinginkan (Standar Deviasi : 10\%)

DDalam mendapatkan populasi $(\boldsymbol{N})$, maka dilakukan perhitungan dengan rata - rata. Berdasarkan rumus Slovin, maka ukuran sampel adalah sebagai berikut:

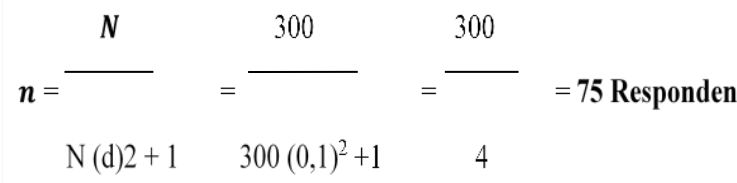

Berdasarkan rumus diatas, maka diperoleh jumlah sampel yang diambil pada penelitian ini adalah 75 orang. Setelah diperoleh jumlah sampel minimal, maka langkah berikutnya 
menentukan teknik pengambilan sampel.

\section{Cara Pengambilan Sampel}

Pengambilan sampel untuk penelitian ini dengan cara purposive sampling yaitu teknik penentuan sampel dengan pertimbangan tertentu (Sugiyono, 2014). Peneliti mencari sampel yaitu pekerja di Proyek Pembangunan Apartemen Evenciio Margonda pada saat waktu senggang atau waktu istirahat, meminta persetujuan, dan meberikan lembar check list kepada responden.

\section{Metode Pengumpulan Data}

Data Primer

Pengumpulan data primer merupakan data yang diperoleh langsung berhubungan dengan responden. Kuesioner digunakan sebagai alat pengumpulan data.

\section{Data Sekunder}

Pengumpulan data sekunder berupa data yang diperoleh dari referensi tertentu atau literature - literature yang berkaitan dengan Permasalahan skripsi yang diambil.

\section{Pengolahan Data}

Pengolahan data dilakukan melalui program aplikasi SPSS 20

Tujuan dari pengolahan hasil penelitian ini adalah untuk memudahkan klasifikasi tiap variabel. Tahapan - tahapan tersebut di antaranya :

1. Editing

2. Coding

3. Procesing

4. Penyajian Data

\section{Analisis Data}

1. Analisis Univariat

Analisis univariat dilakukan untuk menganalisis distribusi frekuensi variabel yang diamati dan diukur sehingga didapatkannya gambaran masing - masing karakteristik tersebut, kemudian disajikan dalam bentuk tabel.

2. Analisis bivariat

Analisis bivariat bertujuan untuk melihat hubungan variabel independen (usia, pengetahuan, motivasi, pengawasan, pelatihan dan ketersediaanAPD) dengan variabel dependen (tindakan tidak aman). Uji yang digunakan dalam analisis bivariat adalah uji chisquare

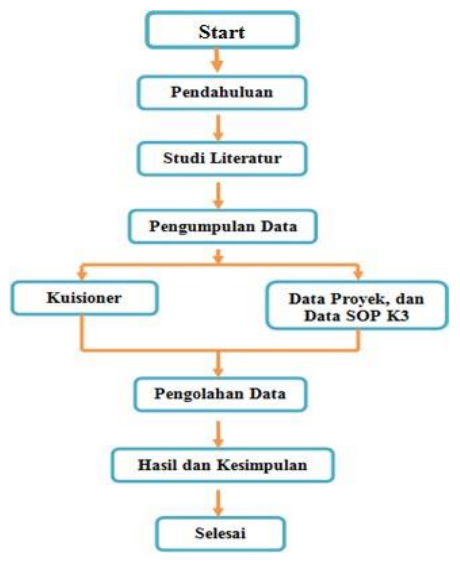

Gambar 1 Bagan alir 
HASIL DAN PEMBAHASAN

\section{Analisis Univariat}

\section{Distribusi Frekuensi Responden Berdasarkan Variabel Tindakan Tidak Aman}

Tabel 1 Distribusi Frekuensi Responden Berdasarkan Variabel Tindakan Tidak Aman

\begin{tabular}{ccc}
\hline Tindakan Tidak Aman & Frekuensi & Persentase \\
\hline Tidak Aman & 33 & $44 \%$ \\
\hline Aman & 42 & $56 \%$ \\
\hline Total & 75 & $100 \%$
\end{tabular}

Berdasarkan pada tabel 1 diatas diketahui bahwa pekerja yang melakukan tindakan tidak aman saat bekerja sebanyak 37 orang dengan persentase $44,0 \%$ serta pekerja yang melakukan tindakan aman saat bekerja sebanyak 42 orang dengan persentase $56,0 \%$.

\section{Distribusi Frekuensi Responden Berdasarkan Variabel Pengetahuan}

Taber 2 responden Berdasarkan Variabel Pengetahuan

\begin{tabular}{ccc}
\hline Pengetahuan & Frekuensi & Persentase \\
\hline Kurang Baik & 14 & $18,7 \%$ \\
\hline Baik & 61 & $81,3 \%$ \\
\hline Total & 75 & $100 \%$
\end{tabular}

Berdasarkan pada tabel 2 diketahui bahwa pengetahuan pekerja yang kurang baik sebanyak 14 orang dengan persentase $18,7 \%$ serta pengetahuan pekerja yang baik sebanyak 61 orang dengan persentase $81,7 \%$.

\section{Distribusi Frekuensi Responden Berdasarkan Variabel Tindakan Motivasi}

Tabel 3 Distribusi Frekuensi Responden Berdasarkan Variabel Pengetahuan

\begin{tabular}{ccc}
\hline Motivasi & Frekuensi & Persentase \\
\hline Rendah & 35 & $46,7 \%$ \\
\hline Tinggi & 40 & $53,3 \%$ \\
\hline Total & 75 & $100 \%$ \\
\hline
\end{tabular}

Berdasarkan pada tabel 3 diatas diketahui bahwa motivasi pekerja yang rendah sebanyak 35 orang dengan persentase $46,7 \%$ dan motivasi pekerja yang tinggi sebanyak 40 orang dengan persentase $53,3 \%$. 
Distribusi Frekuensi Responden Berdasarkan Variabel Tindakan Pengawasan

Tabel 4 Distribusi Frekuensi Responden Berdasarkan Variabel Pengawasan

\begin{tabular}{ccc}
\hline Pengawasan & Frekuensi & Persentase \\
\hline Kurang Baik & 7 & $9,3 \%$ \\
\hline Baik & 68 & $90,7 \%$ \\
\hline Total & 75 & $100 \%$ \\
\hline
\end{tabular}

Berdasarkan pada tabel 4 diketahui bahwa pengawasan kepada pekerja yang dilakukan perusahan dengan baik sebanyak 68 orang dengan persentase $90,7 \%$.

\section{Distribusi Frekuensi Responden Berdasarkan Variabel Tindakan Pelatihan K3}

Tabel 5 Distribusi Frekuensi Responden Berdasarkan Variabel Pelatihan K3

\begin{tabular}{ccc}
\hline Pelatihan K3 & Frekuensi & Persentase \\
\hline Tidak Pernah & 13 & $17,3 \%$ \\
\hline Pernah & 62 & $82,7 \%$ \\
\hline Total & 75 & $100 \%$
\end{tabular}

Berdasarkan pada tabel 5 diketahui bahwa pekerja yang tidak pernah mengikuti pelatihan K3 diperusahaan sebanyak 13 orang dengan persentase $17,3 \%$ dan pekerja yang pernah mengikuti pelatihan $\mathrm{K} 3$ diperusahaan sebanyak 62 orang dengan persentase $82,7 \%$.

\section{Distribusi Frekeunsi Responden Berdasarkan Variabel Tindakan Ketersediaan APD}

Tabel 6 Distribusi Frekuensi Responden Berdasarkan Variabel Ketersediaan APD

\begin{tabular}{ccc}
\hline Ketersediaan APD & Frekuensi & Persentase \\
\hline Kurang tersedia & 8 & $10,7 \%$ \\
\hline Tersedia & 67 & $89,3 \%$ \\
\hline Total & 75 & $100 \%$
\end{tabular}

Berdasarkan pada tabel 6 diketahui bahwa ketersediaan APD di perusahaan untuk pekerja sebanyak 67 orang dengan persentase $97,3 \%$

\section{Analisis Bivariat}

Hubungan Variabel Pengetahuan dengan Variabel TTA 
Tabel 7 Hubungan Antara Pengetahuan dengan Tindakan Tidak Aman

\begin{tabular}{|c|c|c|c|c|c|c|}
\hline \multirow[t]{3}{*}{ Pengetahuan } & \multicolumn{4}{|c|}{$\begin{array}{c}\text { Tindakan Tidak Aman } \\
\text { (TTA) }\end{array}$} & \multicolumn{2}{|c|}{ Total } \\
\hline & \multicolumn{2}{|c|}{ TTA } & \multicolumn{2}{|c|}{ T Aman } & \multirow[t]{2}{*}{$\mathbf{N}$} & \multirow[t]{2}{*}{$\%$} \\
\hline & $\mathbf{N}$ & $\%$ & $\mathbf{N}$ & $\%$ & & \\
\hline Kurang Baik & 11 & & 3 & & 14 & 100 \\
\hline & & 78,5 & & 16 & & \\
\hline Baik & 29 & 47,5 & 32 & 76 & 61 & 100 \\
\hline Total & 33 & 44 & 42 & 56 & 75 & 100 \\
\hline
\end{tabular}

Berdasarkan tabel 4.7 diatas diperoleh 11 orang $(\mathbf{7 8 , 5 \% )}$ pengetahuan kurang baik dengan tindakan bekerja tidak aman, sedangkan terdapat 29 orang $(47,5 \%)$ yang pengetahuan sudah baik dengan tindakan bekerja tidak aman.

\section{Hubungan Variabel Motivasi dengan Variabel TTA}

Tabel 8 Hubungan Antara Motivasi dengan Tindakan Tidak Aman

\begin{tabular}{|c|c|c|c|c|c|c|}
\hline \multirow{3}{*}{ Motivasi } & \multicolumn{4}{|c|}{ Tindakan Tidak Aman (TTA) } & \multicolumn{2}{|c|}{ Total } \\
\hline & \multicolumn{2}{|c|}{ TTA } & \multicolumn{2}{|c|}{ T Aman } & \multirow[t]{2}{*}{$\mathbf{N}$} & \multirow[t]{2}{*}{$\%$} \\
\hline & $\mathbf{N}$ & $\%$ & $\mathbf{N}$ & $\%$ & & \\
\hline Rendah & 24 & 68,5 & 11 & 31,4 & 35 & 100 \\
\hline Tinggi & 16 & 40 & 24 & 60 & 40 & 100 \\
\hline Total & 40 & 53,3 & 35 & 46,7 & 75 & 100 \\
\hline
\end{tabular}

\section{Hubungan Variabel Pengawasan dengan Variabel TTA}

Tabel 9 Hubungan Pengawasan dengan Tindakan Aman

\begin{tabular}{lrrrrrr}
\hline \multirow{2}{*}{ Pengawasan } & \multicolumn{3}{c}{$\begin{array}{c}\text { Tindakan Tidak Aman } \\
\text { (TTA) }\end{array}$} & \multicolumn{2}{c}{ Total } \\
\cline { 2 - 5 } & \multicolumn{2}{c}{ TTA } & \multicolumn{2}{c}{ T Aman } & N & \% \\
\cline { 2 - 5 } & $\mathbf{N}$ & $\mathbf{\%}$ & $\mathbf{N}$ & $\mathbf{\%}$ & & \\
\hline Kurang Baik & 3 & 42,8 & 4 & 57,1 & 7 & 100 \\
\hline Baik & 37 & 54,4 & 31 & 46,7 & 68 & 100 \\
\hline Total & 40 & 53,3 & 35 & 46,7 & 75 & 100 \\
\hline
\end{tabular}

Berdasarkan tabel 9 diatas diperoleh 3 orang $(42,8 \%)$ pengawasan yang kurang baik dengan tindakan bekerja tidak aman, sedangkan terdapat 37 orang $(\mathbf{5 4 , 4 \% )}$ dilakukan pengawasan yang sudah baik dengan tindakan bekerja tidak aman. 
JT : Jurnal Teknik

P-ISSN: 2302-8734

E-ISSN: 2581-0006

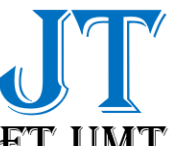

F"T UMT
Vol. 10 No. 1 Th. 2021

Halaman : 1 - 10

Januari 2021

Hubungan Variabel Pelatihan K3 dengan Variabel Tindakan Tidak Aman (TTA)

Tabel 10 Hubungan Pelatihan K3 dengan Tindakan Aman

\begin{tabular}{|c|c|c|c|c|c|c|}
\hline \multirow[t]{3}{*}{$\begin{array}{l}\text { Ketersedia } \\
\text { APD }\end{array}$} & \multicolumn{4}{|c|}{$\begin{array}{l}\text { Tindakan Tidak Aman } \\
\text { (TTA) }\end{array}$} & \multicolumn{2}{|c|}{ Total } \\
\hline & \multicolumn{2}{|c|}{ TTA } & \multicolumn{2}{|c|}{ T Aman } & $\mathbf{N}$ & $\%$ \\
\hline & $\mathbf{N}$ & $\%$ & $\mathbf{N}$ & $\%$ & & \\
\hline Kurang Baik & 2 & 25 & 6 & 75 & 8 & 100 \\
\hline Baik & 38 & 56,7 & 29 & 56,7 & 67 & 100 \\
\hline Total & 40 & 53,3 & 35 & 46,7 & 75 & 100 \\
\hline
\end{tabular}

Berdasarkan tabel 10 diatas diperoleh 8 orang $(\mathbf{6 1 , 5 \% )}$ yang tidak pernah mengikuti pelatihan K3 dengan tindakan bekerja tidak aman, sedangkan terdapat 32 orang $(\mathbf{5 1 , 6 \% )}$ yang pernah mengikuti pelatihan $\mathrm{K} 3$ dengan tindakan bekerja tidak aman.

\section{Hubungan Variabel Ketersediaan APD dengan Variabel Tindakan Tidak Aman}

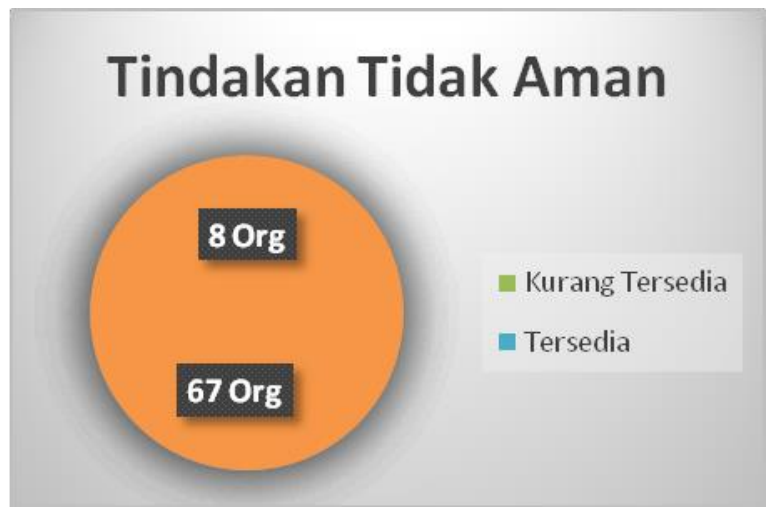

Gambar 2 Hubungan Ketersediaan APD dengan Tindakan tidak aman

Berdasarkan tabel 5 diatas diperoleh 2 orang (25\%) kurang ketersediaan APD dengan tindakan bekerja yang tidak aman, sedangka nterdapat 38 orang $(56,7 \%)$ ketersediaan APD sudah baik dengan tindakan aman dalam bekerja.

\section{SIMPULAN DAN SARAN}

1. Diketahui distribusi frekuensi tindakan tidak aman saat bekerja sebanyak 33 orang dengan persentase $44,0 \%$ dan responden yang melakukan tindakan aman saat bekerja sebanyak 42 orang dengan persentase $56,0 \%$.

2. Diketahui Analisis Univariat distribusi frekuensi pengetahuan kurang baik mengenai K3 sebanyak 14 orang dengan persentase $18,7 \%$ dan responden yang memiliki pengetahuan baik mengenai K3 sebanyak 61 orang dengan persentase $81,3 \%$. Diketahui Hasil Analisis Univariat distribusi frekuensi motivasi rendah sebanyak 35 orang dengan persentase $46,7 \%$ dan responden yang memiliki motivasi tinggi sebanyak 40 orang dengan persentase 53,3\%. Sedangkan Hasil Analisis Bivariat Motivasi responden yang rendah dengan tindakan bekerja yang tidak aman sebanyak 24 orang $(68,5 \%)$ dan motivasi responden yang tinggi dengan tindakan bekerja yang tidak aman 
sebanyak 16 orang $(40 \%)$.

3. Diketahui Hasil Analisis Univariat distribusi frekuensi pengawasan kurang baik sebanyak 7 orang dengan persentase $9,3 \%$ dan responden yang memiliki pengawasan baik sebanyak 68 orang dengan persentase 90,7\%. Sedangkan Hasil Analisis Bivariat Pengawasan responden yang kurang baik dengan tindakan bekerja yang tidak aman sebanyak 3 orang $(42,8 \%)$ dan pengawasan responden yang sudah baik dengan tindakan bekerja yang tidak aman sebanyak 37 orang $(54,4 \%)$.

4. Diketahui Hasil Analisis Univariat distribusi frekuensi tidak pernah mengikuti pelatihan K3 sebanyak 13 orang dengan persentase 17,3\% dan responden yang mengikuti pelatihan K3 sebanyak 62 orang dengan persentase 82,7\%. Sedangkan Hasil Analisis Bivariat Responden yang tidak pernah mengikuti pelatihan K3 dengan tindakan bekerja yang tidak aman sebanyak 8 orang $(61,5 \%)$ dan responden yang pernah mengikuti pelatihan K3 dengan tindakan bekerja yang tidak aman sebanyak 32 orang $(51,6 \%)$.

5. Diketahui Hasil Analisis Univariat distribusi frekuensi kurangnya ketersediaan APD sebanyak 8 orang dengan persentase $10,7 \%$ dan responden yang menyatakan ketersediaan APD sebanyak 67 orang dengan persentase 89,3\%. Sedangkan Hasil Analisis Bivariat Responden yang ketersediaan APD yang kurang tersedia dengan tindakan bekerja yang tidak aman sebanyak 2 orang $(25 \%)$ dan responden yang ketersediaan APD yang tersedia dengan tindakan bekerja yang tidak aman sebanyak 38 orang $(56,7 \%)$.

\section{SARAN}

1. Perusahaan sebaiknya menyediakan media promosi keselamatan yang dapat dipahami oleh pekerja.

2. Sebaiknya pelatihan yang dilakukan pada saat yang tepat dan penyampaian materi dilakukan semenarik mungkin dan lebih menggali pengetahuan.

3. Pihak perusahaan sebaiknya mengadakan penghargaan / reward supaya pekerja lebih termotivasi dalam bekerja.

4. Team Safety perlu mengadakan sanksi / punishment bagi pekerja yang melanggar peraturan

Untuk pekerja, sebaiknya melibatkan diri dan berperan aktif dalam kegiatan pelatihan K3.

\section{DAFTAR PUSTAKA}

Buntarto."DampakDampakTerjadinyaKecelakaanKerja"Rineka Cipta 2018

Depita (2018) Faktor Faktor yang Berhubungan Dengan Perilaku Tindakan Tidak Aman Di Proyek Pembangunan Apartemen Grand Sedayu, Tahun 2018

Ervianto (2005) Permasalahan Dari Segi Kemanusiaan, Biaya dan Manfaat Ekonomi, Aspek Hukum, Pertanggungjawaban Serta Citra Dari Suatu Organisasi Tahun 2005

Erika(2019)" FaktorFaktor yang Berhubungan Dengan Perilaku Tindakan Tidak Aman Di Proyek Pembangunan Apartemen SS Tower Tahun 2019" Skripsi Jakarta : Fakultas Kesehatan Masyarakat 2019.

Frank Bird Jr. Management Guide To Loss Control, Atlanta. : Insititue Press.

Geller O Scoot. The Psychology of safety Handbook. Lewis Publissher, Boca Raton London. New 
York Washington, D.C,2017.

Helliyanti Putri (2009). FaktorFaktor yang Berhubungan Dengan Perilaku Tidak Aman Di Departemen Utility and Operation PT Indofood Sukses Makmur, Tbk Tahun 2009. Skripsi. Depok :Fakultas Kesehatan Masyarakat Universitas Indonesia.

Sri Rejeki, 2015. Sebab SebabTerjadinya Kecelakaan Kerja :Rineka Cipta. 